Check for updates

Cite this: RSC Adv., 2018, 8, 28172

Received 5th July 2018

Accepted 29th July 2018

DOI: $10.1039 / c 8 r a 05722 b$

rsc.li/rsc-advances

\section{Hierarchical $\mathrm{Co}_{3} \mathrm{O}_{4} \mathrm{aCo}_{9} \mathrm{~S}_{8}$ nanowall structures assembled by many nanosheets for high performance asymmetric supercapacitors}

\author{
Lei Xing, Yidi Dong and Xiang Wu (DD *
}

\begin{abstract}
Herein, we report hierarchical $\mathrm{CO}_{3} \mathrm{O}_{4} \mathrm{QCO}_{9} \mathrm{~S}_{8}$ nanowalls assembled by many nanosheets. The as-synthesized products are characterized in detail using various characterization methods. They can be directly used as supercapacitor electrodes with excellent electrochemical performance due to the synergy effect between $\mathrm{CO}_{3} \mathrm{O}_{4}$ and $\mathrm{CO}_{9} \mathrm{~S}_{8}$. Furthermore, a flexible asymmetric supercapacitor is fabricated by using the assynthesized $\mathrm{CO}_{3} \mathrm{O}_{4} \mathrm{aCO}_{9} \mathrm{~S}_{8}$ structures as the cathode and the active carbon as the anode, which reveals a specific capacitance of $266.6 \mathrm{mF} \mathrm{cm}^{-2}$ at a current density of $4 \mathrm{~mA} \mathrm{~cm}^{-2}$. In addition, the supercapacitor shows an excellent capacity retention rate of $86.5 \%$ after 10000 cycles at a current density of $10 \mathrm{~mA}$ $\mathrm{cm}^{-2}$. Finally, three supercapacitor devices connected in series can light a blue LED lamp for 5 min.
\end{abstract}

\section{Introduction}

In recent years, supercapacitors have been a research focus in the energy storage field. It is used widely in portable electronic devices, urban rail transit and uninterruptible power supplies. ${ }^{1-6}$ Supercapacitors are also called electrochemical capacitors, which can be divided in two categories, i.e., electric double layer capacitors that store energy by adsorption of pure electrostatic charge on the surface of the electrode, and pseudocapacitors where reversible redox reactions occur at the surface and near the surface of the electrode material. They inherit the advantages of traditional capacitors with high power density and overcome the disadvantages of low capacitance and complex circuit structure. ${ }^{7,8}$ Compared with traditional batteries, supercapacitors possess characteristics of high charging-discharging speed and long cycle life. ${ }^{\mathbf{9 - 1 1}}$

In general, pseudocapacitor electrode materials such as metal oxides and conductive polymers present higher specific capacitance than double electric layer capacitors. ${ }^{\mathbf{1 2 , 1 3}}$ Recently, various pseudocapacitor electrode materials such as transition metal oxides and sulphides, ${ }^{14-18}$ conductive polymers, ${ }^{19}$ hydroxides ${ }^{\mathbf{2 0 , 2 1}}$ have been reported. Among them, transition metal oxides have relatively high specific surface areas, short electron and ion transmission channels. ${ }^{22}$ Especially, $\mathrm{Co}_{3} \mathrm{O}_{4}$ nanomaterials have received extensive attention due to their excellent electrochemical performance with high theoretical specific capacitance $\left(3560 \mathrm{~F} \mathrm{~g}^{-1}\right.$ ). However, in practice application, single $\mathrm{Co}_{3} \mathrm{O}_{4}$ materials possess poor electrode stability and low cyclic stability. ${ }^{23,24}$ Therefore, one has designed various hybrid structures to use their synergetic effect to improve the

School of Materials Science and Engineering, Shenyang University of Technology, Shenyang 110870, China. E-mail:wuxiang05@163.com electrochemical properties of $\mathrm{Co}_{3} \mathrm{O}_{4}$ nanomaterials. Du et al. successfully synthesized porous $\mathrm{Co}_{3} \mathrm{O}_{4}$ nanosheets@RGo nanocomposite using a simple hydrothermal process. The electrode material exhibits excellent specific capacitance of 894 $\mathrm{F} \mathrm{g}^{-1}$ at a current density of $1 \mathrm{~A} \mathrm{~g}^{-1} \cdot{ }^{25}$ Zhang et al. adjusted surface composition and defects of $\mathrm{Co}_{3} \mathrm{O}_{4}$ electrode material by controlling the calcination temperature to improve the electrochemical performance. The electrode material shows a high specific capacitance $\left(739 \mathrm{~F} \mathrm{~g}^{-1}\right.$ at $\left.5 \mathrm{mV} \mathrm{s}^{-1}\right)$ and has excellent cycle stability. ${ }^{26}$

Herein, we successfully fabricated hierarchical $\mathrm{Co}_{3} \mathrm{O}_{4} @ \mathrm{Co}_{9}$ $\mathrm{S}_{8}$ nanowalls on the nickel foam by a continuous hydrothermal method and used them as the cathodes for a flexible and quasisolid supercapacitor. In this heterostructure, the original $\mathrm{Co}_{3} \mathrm{O}_{4}$ nanosheets will serve as the support skeletons for $\mathrm{Co}_{9} \mathrm{~S}_{8}$ growth. The $\mathrm{Co}_{9} \mathrm{~S}_{8}$ layers are not only can enhance the capacitance but also acts as a conductive layer to shorten the ion diffusion distance. The detailed electrochemical tests show that the specific capacitances can reach $4523.6 \mathrm{mF} \mathrm{cm}^{-2}$ and $1512.7 \mathrm{~F}$ $\mathrm{g}^{-1}$ at current density of $4 \mathrm{~mA} \mathrm{~cm}^{-2}$ and $4 \mathrm{~A} \mathrm{~g}^{-1}$. An asymmetric supercapacitor is assembled using $\mathrm{Co}_{3} \mathrm{O}_{4} @ \mathrm{Co}_{9} \mathrm{~S}_{8}$ nanowalls electrode as the cathode and activated carbon (AC) as the anode material, respectively. The fabricated supercapacitor shows good electrochemical performance with the energy density of $0.416 \mathrm{~mW} \mathrm{~h} \mathrm{~cm}^{-3}$ when power density reach $14.994 \mathrm{~W} \mathrm{~cm}^{-3}$.

\section{Experimental details}

\subsection{Material preparation}

For the synthesis, all the chemicals were analytical grade and used as received without further purification. $\mathrm{Co}_{3} \mathrm{O}_{4}$ nanowalls were grown on nickel foam by a simple hydrothermal method. In order to remove the oxide layer from nickel foam, it was 
treated with $2 \mathrm{M}$ hydrochloric acid followed by ultrasonic cleaning using distilled water and alcohol, sequentially. In a typical synthesis process, $0.582 \mathrm{~g}$ of $\mathrm{Co}\left(\mathrm{NO}_{3}\right)_{2}, 0.185 \mathrm{~g}$ of $\mathrm{NH}_{4} \mathrm{~F}$ and $0.6 \mathrm{~g}$ of urea are dissolved in $60 \mathrm{ml}$ of distilled water and stirred for $30 \mathrm{~min}$ to form a stable suspension. The solution was then transferred to a Teflon-lined stainless steel autoclave and the pre-treated nickel foam was immersed in the aqueous solution. The autoclave was then sealed and heated to $120^{\circ} \mathrm{C}$ for $6 \mathrm{~h}$. After completing the reaction at desired time, the autoclave was cooled to room temperature and the as-obtained product was washed several times to remove un-reacted reactants. The product was finally dried at $60^{\circ} \mathrm{C}$ for $6 \mathrm{~h}$ and calcined at $350{ }^{\circ} \mathrm{C}$ for $2 \mathrm{~h}$ in a muffle furnace. Hierarchical $\mathrm{Co}_{3} \mathrm{O}_{4} @ \mathrm{Co}_{9} \mathrm{~S}_{8}$ nanowalls were synthesized via a same hydrothermal process. In detail, $0.35 \mathrm{~g} \mathrm{Na} \mathrm{N}_{2} \mathrm{~S} \cdot 2 \mathrm{H}_{2} \mathrm{O}, 50 \mathrm{ml}$ DI water and the as-prepared $\mathrm{Co}_{3} \mathrm{O}_{4}$ nanosheet on $\mathrm{Ni}$ foam were placed into a $100 \mathrm{ml}$ Teflon-lined autoclave. The temperature was maintained at $120{ }^{\circ} \mathrm{C}$ for $6 \mathrm{~h}$ and then cooled down to room temperature naturally.

\subsection{Material characterizations}

The phase and crystallinity of the as-prepared products were characterized by X-ray powder diffraction (XRD, Rigaku Dmax$\mathrm{rB}, \mathrm{Cu}-\mathrm{K} \alpha$ radiation, $\lambda=0.1542 \mathrm{~nm}, 40 \mathrm{kV}, 100 \mathrm{~mA})$. The morphology and microstructure of the as-synthesized samples were studied by scanning electron microscopy (Gemini SEM 300) and the chemical bonding states of the samples were examined using XPS measurements. The electrochemical workstation (CHI660E) was used to test the electrochemical properties.

\subsection{Electrochemical measurements}

Electrochemical tests of $\mathrm{Co}_{3} \mathrm{O}_{4}$ and $\mathrm{Co}_{3} \mathrm{O}_{4} @ \mathrm{Co}_{9} \mathrm{~S}_{8}$ product as the working electrode were performed in $2 \mathrm{M} \mathrm{KOH}$ aqueous solution using a three-electrode system. The counter and reference electrodes were $\mathrm{Pt}$ electrode and $\mathrm{Hg} / \mathrm{HgO}$ electrode, respectively. The working electrode area was $0.785 \mathrm{~cm}^{2}$, and the average load capacity of $\mathrm{Co}_{3} \mathrm{O}_{4} @ \mathrm{Co}_{9} \mathrm{~S}_{8}$ nanowalls in nickel foam was $2.70 \mathrm{mg} \mathrm{cm}^{-2}$. The work voltage was applied in the range of 0 to $0.55 \mathrm{~V}$, and the curve was scanned at 5, 10, 20, 50, $100 \mathrm{mV}$ $\mathrm{s}^{-1}$, respectively. GCD curves were measured at current densities of $4,8,10,12$ and $20 \mathrm{mF} \mathrm{cm}^{-2}$. The electrochemical impedance spectra (EIS) studies were performed in the frequency range from $0.01 \mathrm{kHz}$ to $100 \mathrm{MHz}$ with an amplitude of $10 \mathrm{mV}$. Area capacitance, energy density and power density of electrode materials were calculated according to the eqn (1)-(4), respectively as below:

$$
\begin{gathered}
C_{\mathrm{a}}=\frac{I \Delta t}{\Delta S \Delta V} \\
C_{\mathrm{sp}}=\frac{I \Delta t}{m \Delta V} \\
E=\frac{1}{2} C V^{2}
\end{gathered}
$$

$$
P=\frac{E}{\Delta t}
$$

where $I$ is the constant discharge current, $\Delta t$ is the discharge time, $\Delta S$ is the area of the working electrode, $\Delta V$ is the potential window, $C_{\mathrm{a}}$ is the area capacitance, $C_{\mathrm{sp}}$ is the mass specific capacitance and $V$ refers to the potential changes.

\subsection{Flexible asymmetric supercapacitor}

To prepare the solid-state ASC devices, solid-state $\mathrm{Co}_{3} \mathrm{O}_{4} @ \mathrm{Co}_{9} \mathrm{~S}_{8}$ nanowalls//AC devices with $\mathrm{Co}_{3} \mathrm{O}_{4} @ \mathrm{Co}_{9} \mathrm{~S}_{8}$ nanosheet arrays as the cathode and AC as the anode. The separator (NKK separator, Nippon Kodoshi Corporation) and polymer electrolyte using $\mathrm{PVA} / \mathrm{KOH}$ gel were used. To optimize the charges between the two electrodes, the area ratio of $\mathrm{Co}_{3} \mathrm{O}_{4} @ \mathrm{Co}_{9} \mathrm{~S}_{8}$ nanowalls electrode to AC electrode was $1: 1$. PVA/KOH gel were prepared by dissolving $5 \mathrm{~g}$ of PVA and $3 \mathrm{~g}$ of $\mathrm{KOH}$ in $50 \mathrm{ml}$ of distilled water and heated to $80{ }^{\circ} \mathrm{C}$ for $1 \mathrm{~h}$ under continuous stirring. The electrode and the separator were immersed in $\mathrm{PVA} / \mathrm{KOH}$ electrolyte.

\section{Results and discussion}

The crystallinity and crystal phases of the as-prepared products are first examined by X-ray diffraction. Fig. 1a demonstrates typical XRD pattern of $\mathrm{Co}_{3} \mathrm{O}_{4}$ nanowalls grown on $\mathrm{Ni}$ foam. The diffraction peaks located at $44.6^{\circ}, 52.0^{\circ}$ and $76.6^{\circ}$ correspond to nickel peaks (JCPDS card no. 42-0712) from Ni foam. Several other diffraction peaks at $31.3^{\circ}, 36.9^{\circ}, 55.7^{\circ}, 59.4^{\circ}$ and $65.2^{\circ}$ correspond to (220), (311), (422), (511) and (440) $\mathrm{Co}_{3} \mathrm{O}_{4}$ crystal planes (JCPDS card no. 42-1467), respectively. Fig. 1b shows XRD pattern of hybrid products. It exhibits several well defined diffraction peaks. Diffraction peaks at $21.7^{\circ}, 37.7^{\circ}, 55.1^{\circ}$ are found to be $\mathrm{Ni}_{3} \mathrm{~S}_{2}$ (JCPDS card no. 44-1418) due to the reaction of nickel foam with $\mathrm{Na}_{2} \mathrm{~S} \cdot 2 \mathrm{H}_{2} \mathrm{O}$. Other five diffraction peaks located at $29.7^{\circ}, 39.4^{\circ}, 44.8^{\circ}, 61.7^{\circ}$ and $73.3^{\circ}$ are seen, which correspond to $\mathrm{Co}_{9} \mathrm{~S}_{8}$ crystal planes of (311), (331), (422), (622) and (731), respectively. No characteristic peaks of other impurities are detected, indicating that the as-synthesized $\mathrm{Co}_{3} \mathrm{O}_{4} @$ $\mathrm{Co}_{9} \mathrm{~S}_{8}$ products have high purity. The well-defined and strong diffraction peaks clearly confirm well crystallinity of the synthesized samples.

Fig. 1c shows XPS full spectrum of $\mathrm{Co}_{3} \mathrm{O}_{4} @ \mathrm{Co}_{9} \mathrm{~S}_{8}$ product. The main five characteristic peaks of $\mathrm{Co}, \mathrm{O}, \mathrm{S}, \mathrm{Ni}$ and $\mathrm{C}$ are detected in XPS spectrum. Fig. 1d presents the Co 2p XPS fitting spectrum. The Co 2p spectrum exhibits two spin-orbit doublets characteristic of $\mathrm{Co}^{2+}$ and $\mathrm{Co}^{3+}$ and two shake-up satellites. The two major peaks with a high energy band at $778.7 \mathrm{eV}$ for Co $2 \mathrm{p}_{3 / 2}$ and a low energy band at $794.5 \mathrm{eV}$ for Co $2 \mathrm{p}_{1 / 2}$ are in accordance with the presence of $\mathrm{Co}_{3} \mathrm{O}_{4} @ \mathrm{Co}_{9} \mathrm{~S}_{8}$. The O 1s spectrum (Fig. 1e) also can be divided into three peaks centered at 528.0, 528.8 and $529.6 \mathrm{eV}$, which correspond to oxygen in the $\mathrm{Co}_{3} \mathrm{O}_{4}$, oxygen atoms in hydroxyl group as well as the absorbed water, respectively. Fig. If clearly demonstrates the XPS spectrum of the S 2p. S can be further identified by the two distinct 2p peaks at $159.9 \mathrm{eV}$ and $165.9 \mathrm{eV}$. The XPS results further confirm the presence of $\mathrm{Co}_{3} \mathrm{O}_{4}$ and $\mathrm{Co}_{9} \mathrm{~S}_{8}$ phases in the prepared $\mathrm{Co}_{3} \mathrm{O}_{4} @ \mathrm{Co}_{9} \mathrm{~S}_{8}$ product. $^{27}$ 

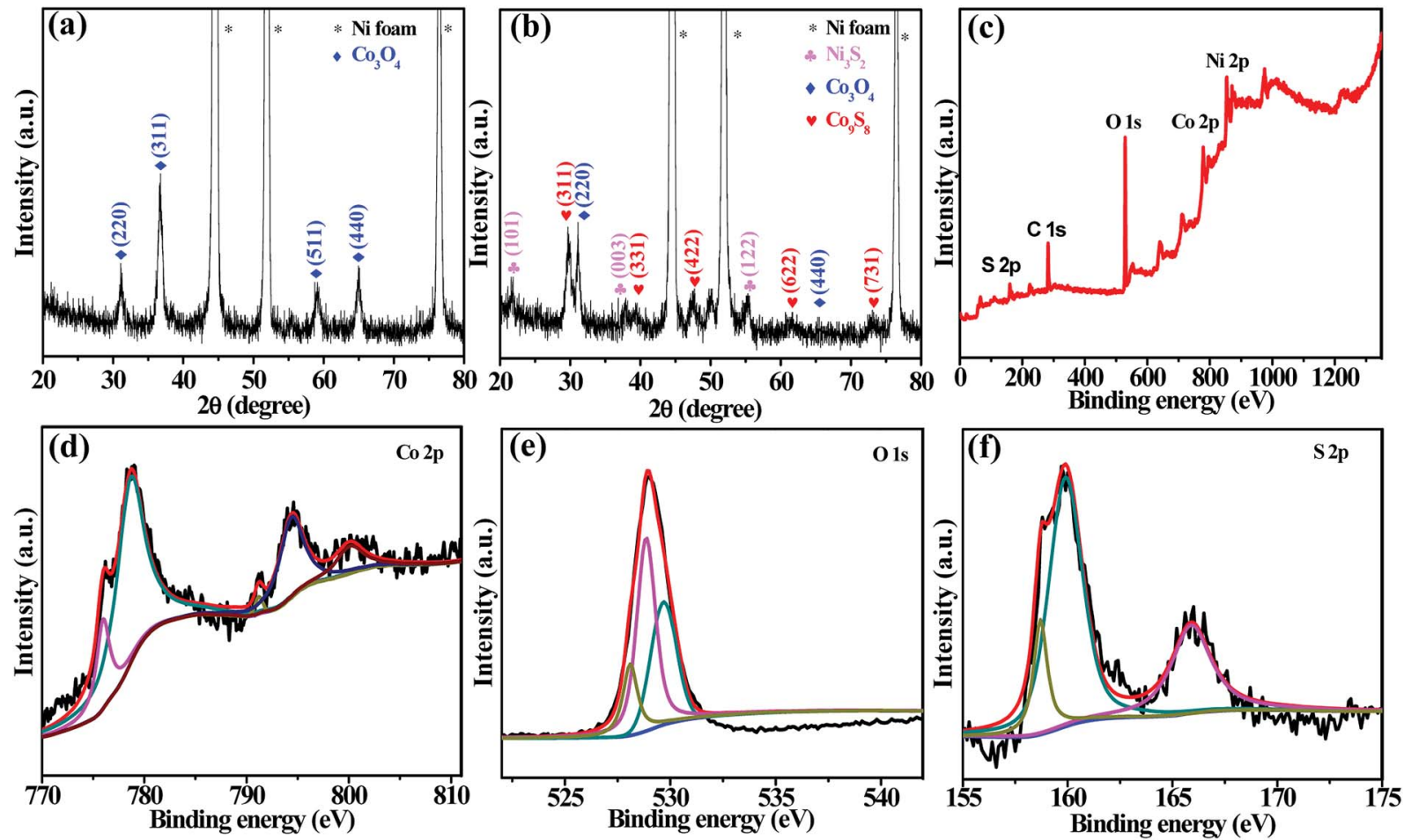

Fig. 1 (a) XRD patterns of $\mathrm{Co}_{3} \mathrm{O}_{4}$ nanowalls (b) XRD patterns of $\mathrm{Co}_{3} \mathrm{O}_{4} \mathrm{aCo}_{9} \mathrm{~S}_{8}$ nanowalls (c) XPS spectra of as-synthesized $\mathrm{Co}_{3} \mathrm{O}_{4} @ \mathrm{CCO}_{9} \mathrm{~S}_{8}$ nanowalls $(d-f) X P S$ survey scan of $\mathrm{Co} 2 p, O$ 1s and $S 2 p$ regions, respectively.

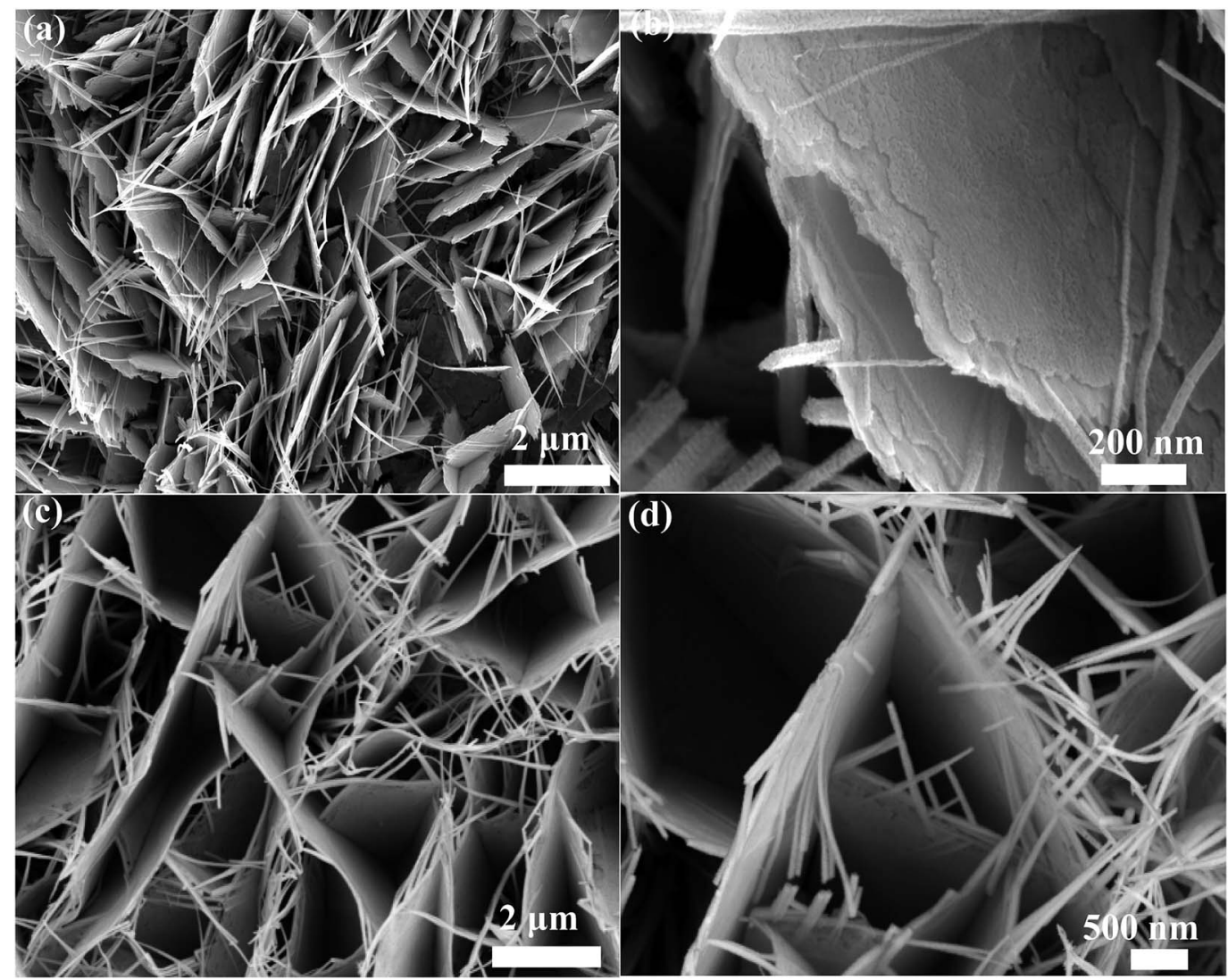

Fig. 2 (a and b) SEM images of $\mathrm{Co}_{3} \mathrm{O}_{4}$ nanowalls grown on $\mathrm{Ni}$ foam (c and d) SEM images of $\mathrm{Co}_{3} \mathrm{O}_{4} \mathrm{CCO}_{9} \mathrm{~S}_{8}$ nanowalls. 
The morphology of $\mathrm{Co}_{3} \mathrm{O}_{4}$ nanowalls and $\mathrm{Co}_{3} \mathrm{O}_{4} @ \mathrm{Co}_{9} \mathrm{~S}_{8}$ nanowalls are observed using SEM. Fig. 2a and b show the general morphology of $\mathrm{Co}_{3} \mathrm{O}_{4}$ nanosheets on nickel foam. It can be clearly seen that $\mathrm{Co}_{3} \mathrm{O}_{4}$ nanosheets are woven by many nanowires. The surface texture of the nanosheets is not uniform and clearly showing porous characteristic. $\mathrm{Co}_{3} \mathrm{O}_{4}$ nanosheet thickness is about $20 \mathrm{~nm}$. Fig. 2c and d show SEM images of $\mathrm{Co}_{3} \mathrm{O}_{4} @ \mathrm{Co}_{9} \mathrm{~S}_{8}$ nanowalls. Many $\mathrm{Co}_{3} \mathrm{O}_{4} @ \mathrm{Co}_{9} \mathrm{~S}_{8}$ nanosheets are well aligned on $\mathrm{Ni}$ foam. The typical thickness of $\mathrm{Co}_{3} \mathrm{O}_{4} @ \mathrm{Co}_{9} \mathrm{O}_{8}$ nanosheets is in the range of $30 \pm 5 \mathrm{~nm}$.

Electrochemical properties of $\mathrm{Co}_{3} \mathrm{O}_{4}$ and $\mathrm{Co}_{3} \mathrm{O}_{4} @ \mathrm{Co}_{9} \mathrm{~S}_{8}$ nanowalls in $2 \mathrm{M} \mathrm{KOH}$ aqueous solution are studied. Fig. 3a shows the cyclic voltammetry of $\mathrm{Co}_{3} \mathrm{O}_{4}, \mathrm{Ni}_{3} \mathrm{~S}_{2}$ and $\mathrm{Co}_{3} \mathrm{O}_{4} @ \mathrm{Co}_{9} \mathrm{~S}_{8}$ product at sweep rate of $100 \mathrm{mV} \mathrm{s}^{-1}$. It can be seen that all samples present pseudocapacitive CV curves. Remarkably, the contribution from $\mathrm{Ni}_{3} \mathrm{~S}_{2}$ can be negligible due to the small integrated area. At the same time, the closed area of CV curve of $\mathrm{Co}_{3} \mathrm{O}_{4} @ \mathrm{Co}_{9} \mathrm{~S}_{8}$ electrode is much larger than that of the original $\mathrm{Co}_{3} \mathrm{O}_{4}$. The improved capacitance results from the increased reactive sites due to a plenty of $\mathrm{Co}_{9} \mathrm{~S}_{8}$ nanocrystals wrapped over the $\mathrm{Co}_{3} \mathrm{O}_{4}$ nanosheet effectively. As shown in Fig. $3 \mathrm{~b}$, the galvanostatic charging/discharging measurements of $\mathrm{Co}_{3} \mathrm{O}_{4}, \mathrm{Ni}_{3} \mathrm{~S}_{2}$ and $\mathrm{Co}_{3} \mathrm{O}_{4} @ \mathrm{Co}_{9} \mathrm{~S}_{8}$ product are further conducted at current density of $4 \mathrm{~mA} \mathrm{~cm}^{-2}$. As expected, the $\mathrm{Co}_{3} \mathrm{O}_{4} @ \mathrm{Co}_{9} \mathrm{~S}_{8}$ electrode exhibits much longer discharging time than $\mathrm{Co}_{3} \mathrm{O}_{4}$ electrode. According to the formula (1), area capacitance $\mathrm{Co}_{3} \mathrm{O}_{4} @ \mathrm{Co}_{9} \mathrm{~S}_{8}$ product can reach $4523.6 \mathrm{mF} \mathrm{cm}{ }^{-2}$. The capacity of $\mathrm{Co}_{3} \mathrm{O}_{4}$ and $\mathrm{Ni}_{3} \mathrm{~S}_{2}$ reach only $464.2 \mathrm{mF} \mathrm{cm} \mathrm{cm}^{-2}$ and $111.2 \mathrm{mF} \mathrm{cm}^{-2}$. The main reason for the increase in capacity may be the synergy effect between the $\mathrm{Co}_{3} \mathrm{O}_{4}$ and $\mathrm{Co}_{9} \mathrm{~S}_{8} \cdot{ }^{28}$ Fig. 3c shows the electrochemical impedance spectroscopy (EIS) of the original $\mathrm{Co}_{3} \mathrm{O}_{4}$, $\mathrm{Ni}_{3} \mathrm{~S}_{2}$ and $\mathrm{Co}_{3} \mathrm{O}_{4} @ \mathrm{Co}_{9} \mathrm{~S}_{8}$ product. It can be observed that the Nyquist plots consist of a linear part in low frequency region and a semicircle part in high frequency region. The slope of the straight line in the low-frequency region is associated with the diffusive resistance. Their nearly vertical slope demonstrates the fast ion diffusion and the ideal capacitive behavior of these electrodes. Besides, the intercept of the plots at the $X$ axis in high-frequency range represents the equivalent series resistance (ESR) of the electrodes. The intercept of the Nyquist curve on the real axis is about $0.76 \Omega$, indicating that $\mathrm{Co}_{3} \mathrm{O}_{4} @ \mathrm{Co}_{9} \mathrm{~S}_{8}$ electrode has good conductivity and low internal resistance. Similarly, the $\mathrm{Co}_{3} \mathrm{O}_{4} @ \mathrm{Co}_{9} \mathrm{~S}_{8}$ nanosheet arrays electrode shows much smaller semicircle diameter in high-frequency range than
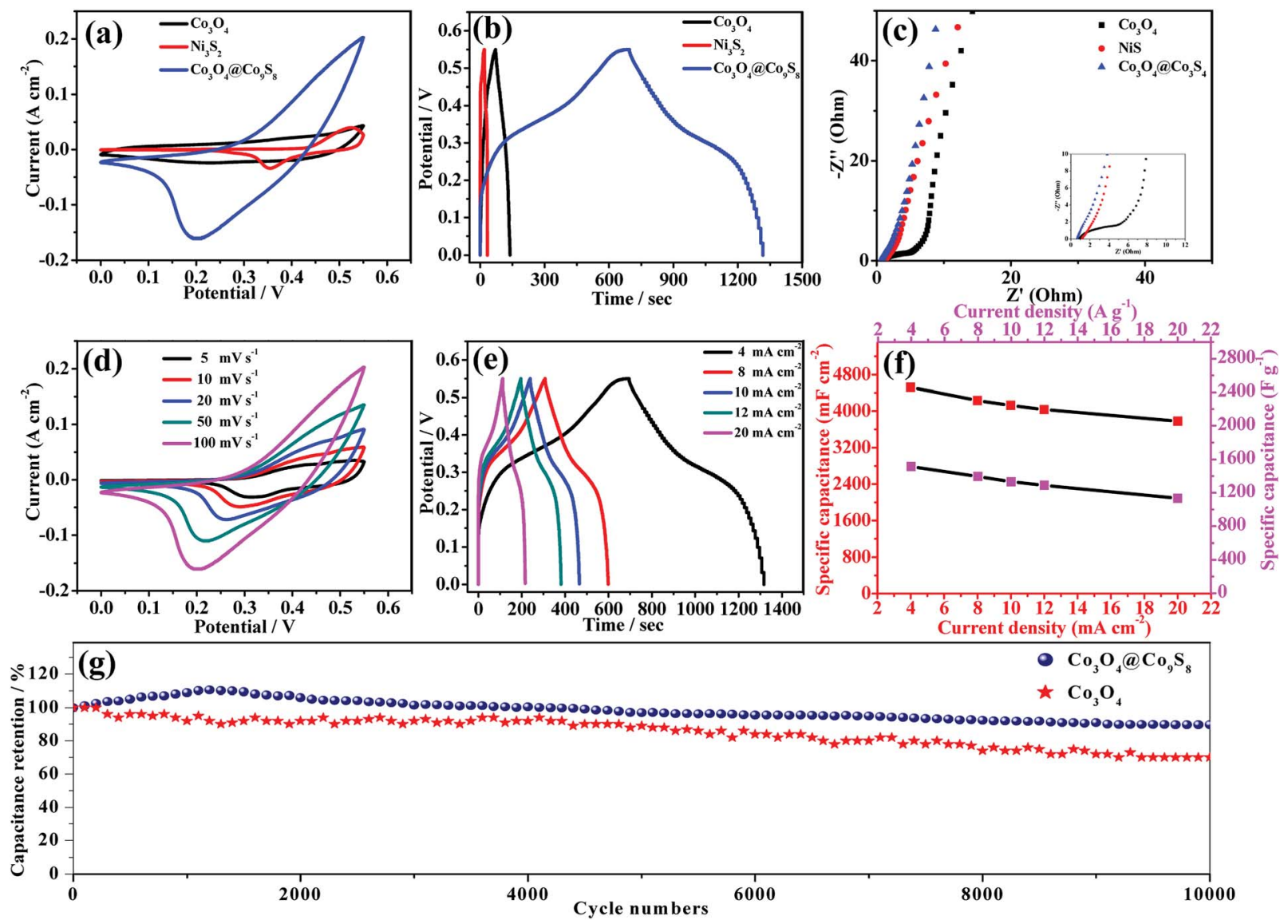

Fig. 3 (a) $\mathrm{CV}$ curves of $\mathrm{CO}_{3} \mathrm{O}_{4}$ nanowalls, $\mathrm{Ni}_{3} \mathrm{~S}_{2}$ samples and $\mathrm{CO}_{3} \mathrm{O}_{4}\left(\mathrm{aCo}_{9} \mathrm{~S}_{8}\right.$ electrodes collected at $100 \mathrm{mV} \mathrm{s} \mathrm{s}^{-1}$ (b) galvanostatic chargedischarge curves collected for the $\mathrm{CO}_{3} \mathrm{O}_{4}$ nanosheets, $\mathrm{Ni}_{3} \mathrm{~S}_{2}$ and $\mathrm{CO}_{3} \mathrm{O}_{4} \mathrm{aCO}_{9} \mathrm{~S}_{8}$ electrodes at $4 \mathrm{~mA} \mathrm{~cm}^{-2}$ (c) Nyquist plots of $\mathrm{CO}_{3} \mathrm{O}_{4}$ nanosheets, $\mathrm{Ni}_{3} \mathrm{~S}_{2}$ and $\mathrm{CO}_{3} \mathrm{O}_{4} \mathrm{QCO}_{9} \mathrm{~S}_{8}$ electrodes (d) $\mathrm{CV}$ curves of $\mathrm{CO}_{3} \mathrm{O}_{4} \mathrm{CCO}_{9} \mathrm{~S}_{8}$ nanowalls at different scan rates (e) charge-discharge behavior of $\mathrm{CO}_{3}-$ $\mathrm{O}_{4} \mathrm{aCo}_{9} \mathrm{~S}_{8}$ nanowalls at different current densities (f) specific capacitance and areal capacitance of the as-obtained $\mathrm{Co}_{3} \mathrm{O}_{4} \mathrm{aCO}_{9} \mathrm{~S}_{8}$ nanowalls at different current densities $(\mathrm{g})$ cycling performance and capacitance retention of $\mathrm{Co}_{3} \mathrm{O}_{4} \mathrm{QCO}_{9} \mathrm{~S}_{8}$ nanowalls and $\mathrm{Co}_{3} \mathrm{O}_{4}$ nanosheets electrode at a current density of $20 \mathrm{~mA} \mathrm{~cm} \mathrm{~cm}^{-2}$. 
that of $\mathrm{Co}_{3} \mathrm{O}_{4}$ electrode. The low $R_{\mathrm{ct}}$ is beneficial to fast charge transfer, which is derived from excellent infiltration of electrolyte and the shortened diffusion path of ions. ${ }^{29}$

In order to study the influence of the scan rates on the electrochemical performance of $\mathrm{Co}_{3} \mathrm{O}_{4} @ \mathrm{Co}_{9} \mathrm{~S}_{8}$ electrode, CV curves of the samples are performed at various scan rates ranging from 5 to $100 \mathrm{mV} \mathrm{s}^{-1}$, as shown in Fig. 3d. It can be seen that the redox peaks of $\mathrm{Co}_{3} \mathrm{O}_{4} @ \mathrm{Co}_{9} \mathrm{~S}_{8}$ electrode move to both sides as the scan rate increases due to the polarization effect of the electrodes. In order to get more information about the performance of $\mathrm{Co}_{3} \mathrm{O}_{4}$ @ $\mathrm{Co}_{9} \mathrm{~S}_{8}$ electrodes, a series of chargedischarge test are carried out at a voltage range of $0-0.55 \mathrm{~V}$ with current densities of 4, 8, 10, 12 and $20 \mathrm{~mA} \mathrm{~cm}^{-2}$. As shown in Fig. 3e, all the galvanostatic charging/discharging plots show a typical nonlinear behavior at different current densities ranging from 4 to $20 \mathrm{~mA} \mathrm{~cm} \mathrm{~cm}^{-2}$, revealing pseudocapacitive nature of the samples. Fig. $3 \mathrm{f}$ shows the area specific capacitance of $\mathrm{Co}_{3} \mathrm{O}_{4} @ \mathrm{Co}_{9} \mathrm{~S}_{8}$ electrodes at different current densities. The area capacitances of $\mathrm{Co}_{3} \mathrm{O}_{4} @ \mathrm{Co}_{9} \mathrm{~S}_{8}$ electrodes are 4523.6, 4232.7, 4127.2, 4036.3 and $3781.8 \mathrm{mF} \mathrm{cm}^{-2}$ at current densities of $4,8,10,12$ and $20 \mathrm{~mA} \mathrm{~cm}^{-2}$, respectively. Similarly, according to formula (2), the mass specific capacitance of $\mathrm{Co}_{3} \mathrm{O}_{4} @ \mathrm{Co}_{9} \mathrm{~S}_{8}$ electrodes are 1512.7, 1396.3, 1330.9, 1289.4 and $1134.5 \mathrm{~F} \mathrm{~g}^{-1}$ at current densities of $4,8,10,12$ and $20 \mathrm{~A} \mathrm{~g}^{-1}$ respectively. To test the cycle stability of the as-prepared samples, the repeated charge and discharge cycled are performed at a current density of $20 \mathrm{~mA} \mathrm{~cm}^{-2}$, as shown in Fig. $3 \mathrm{~g}$. Their specific capacitance gradually increases in the initial phase, which might be attributed to gradual activation of the active materials. After 10000 charge and discharge cycles the specific capacitance reduce to $4057.6 \mathrm{mF} \mathrm{cm} \mathrm{cm}^{-2}$, which is equivalent the retention rate of
$89.7 \%$. The excellent cycling stability is mainly attributed to many vacancies, from rough surface effect, which can not only lead to more contact area with the electrolyte, but also accommodate possible volume change during cycling process. ${ }^{\mathbf{3 0 , 3 1}}$

To further investigate the practical application of the assynthesized electrode materials, a asymmetric supercapacitor is assembled using $\mathrm{AC}$ as anode, $\mathrm{Co}_{3} \mathrm{O}_{4} @ \mathrm{Co}_{9} \mathrm{~S}_{8}$ nanowalls as cathode and the typical $\mathrm{PVA} / \mathrm{KOH}$ as gel-like electrolyte (denoted as $\mathrm{Co}_{3} \mathrm{O}_{4} @ \mathrm{Co}_{9} \mathrm{~S}_{8} / /$ AC ASC). According to the charge balance $\left(q^{+}=q^{-}\right)$, the mass balance between the positive and negative electrode can be obtained via $\mathrm{m}^{-} / \mathrm{m}^{+}=\left(C^{+} \times \Delta V^{+}\right) /\left(C^{-} \times \Delta V^{-}\right)$, where $C^{+}$and $C^{-}$is the capacitance of the electrodes, $\Delta V^{+}$and $\Delta V$ is the corresponding voltage range for charging-discharging process, hence the loading mass of AC electrode is $\sim 14.4$ $\mathrm{mg} \mathrm{cm}{ }^{-2}$ after balance. Before assembling, CV curves of both $\mathrm{AC}$ electrode and $\mathrm{Co}_{3} \mathrm{O}_{4} @ \mathrm{Co}_{9} \mathrm{~S}_{8}$ electrode are tested at the scan rate of $100 \mathrm{mV} \mathrm{s}^{-1}$ in a three-electrode system, as shown in Fig. 4a. Based on the single-electrode $\mathrm{CV}$ curve, $\mathrm{AC}$ and $\mathrm{Co}_{3}$ $\mathrm{O}_{4} @ \mathrm{Co}_{9} \mathrm{~S}_{8}$ product provide a stable voltage window between -1 to $0 \mathrm{~V}$ and $0-0.55 \mathrm{~V}$, respectively. Therefore, when assembled into a flexible asymmetric supercapacitor, the operating voltage could be extended to approximately $1.6 \mathrm{~V}$. Fig. 4b shows the CV curve of $\mathrm{Co}_{3} \mathrm{O}_{4} @ \mathrm{Co}_{9} \mathrm{~S}_{8}$ nanowalls//AC ASC at a swept rate of $100 \mathrm{mV} \mathrm{s}^{-1}$ and a voltage window of 0.9-1.6 V. All the curves show that $\mathrm{Co}_{3} \mathrm{O}_{4} @ \mathrm{Co}_{9} \mathrm{~S}_{8}$ nanowalls//AC ASC operates at a $1.6 \mathrm{~V}$ operating voltage. From Fig. 4c, the as-prepared asymmetric supercapacitor is tested at various scan rates ranging from 10 to $50 \mathrm{mV} \mathrm{s}^{-1}$ in the potential window of 0 to $1.5 \mathrm{~V}$. As the scan rate increased, closed areas are augmentative while the shapes remain quasi-rectangular. The quasi-rectangular CV geometry indicates the obvious redox characteristics. Galvanostatic
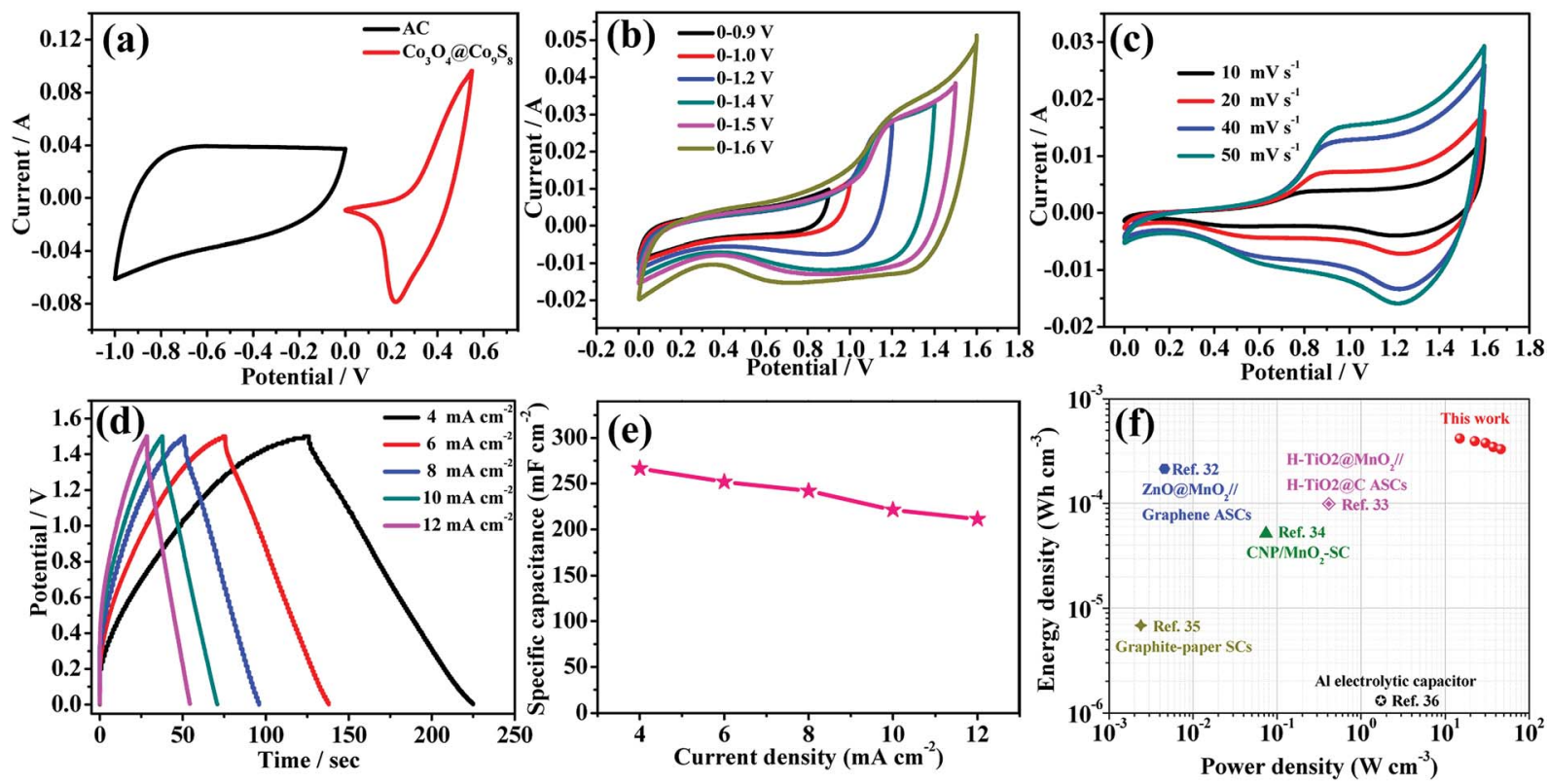

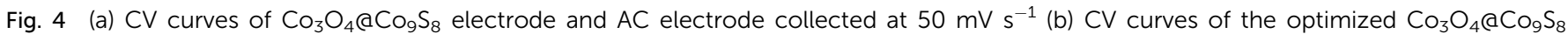
nanowalls//AC ASC device collected within various operation voltage windows (c) CV curves of the optimized $\mathrm{Co}_{3} \mathrm{O}_{4} \mathrm{CCO}_{9} \mathrm{~S}_{8}$ nanowalls//AC ASC device collected at various scan rates (d) charge-discharge curves of the optimized $\mathrm{CO}_{3} \mathrm{O}_{4} \mathrm{CCO}_{9} \mathrm{~S}_{8}$ nanowalls//AC ASC device collected at various current densities (e) area specific capacitance of $\mathrm{CO}_{3} \mathrm{O}_{4}\left(\mathrm{aCO}_{9} \mathrm{~S}_{8}\right.$ nanowalls//AC ASC device at different sweep rates (f) Ragone plot of $\mathrm{CO}_{3} \mathrm{O}_{4} \mathrm{aCo}_{9} \mathrm{~S}_{8}$ nanowalls//AC ASC. 

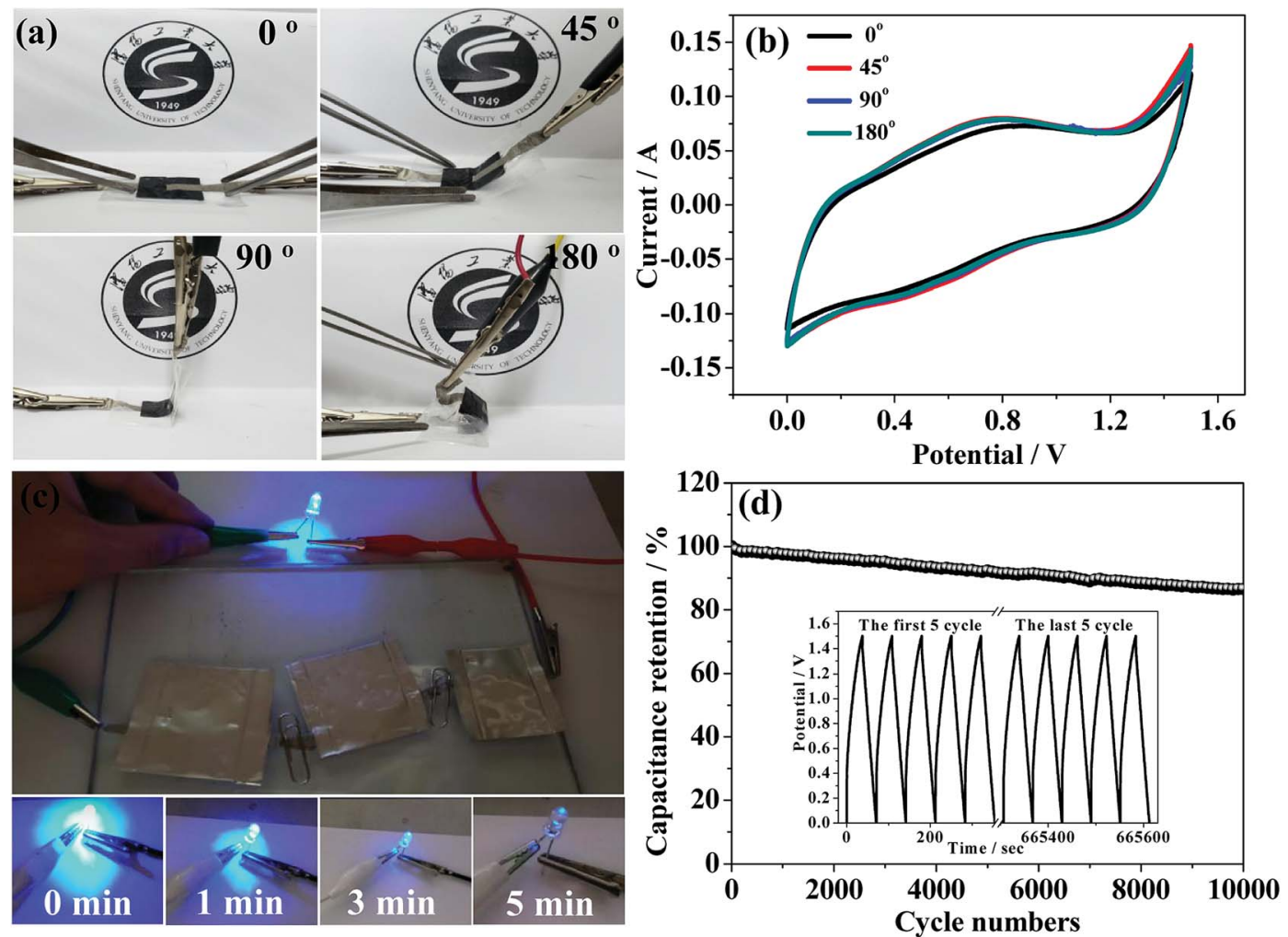

Fig. 5 (a) CV profile of the fabricated flexible ASC cell with different bending angles at a scan rate of $100 \mathrm{mV} \mathrm{s}^{-1}$ (b) image of the bent cells (c) the photograph of the device in series lighting the blue LED (d) cycling performance of $\mathrm{CO}_{3} \mathrm{O}_{4} \mathrm{aCO} \mathrm{CO}_{8} / / \mathrm{AC}$ ASCs collected at a current density of 10 $\mathrm{mA} \mathrm{cm}{ }^{-2}$ for 10000 cycles, and the inset is galvanostatic charge/discharge curves at the first and the last 5 cycles.

charging/discharging testing of $\mathrm{Co}_{3} \mathrm{O}_{4} @ \mathrm{Co}_{9} \mathrm{~S}_{8} / / \mathrm{AC}$ ASC under various current densities are shown in Fig. $4 \mathrm{~d}$. The chargedischarge curves are almost symmetrical, revealing the perfect electrochemical behavior of the as-prepared asymmetric supercapacitor. Fig. 4e shows area specific capacitance of 266.6, $252.0,242.0,221.3,211.2 \mathrm{mF} \mathrm{cm}^{-2}$ at the current density of 4,6 , $8,10,12 \mathrm{~mA} \mathrm{~cm}^{-2}$, respectively. Fig. $4 \mathrm{f}$ is a Ragone plot based on energy density and power density of a asymmetric supercapacitor. At a current density of $4 \mathrm{~mA} \mathrm{~cm}^{-2}$, its power density is $14.99 \mathrm{~W} \mathrm{~cm}^{-3}$, and its maximum energy density is $0.416 \mathrm{~mW} \mathrm{~h}$ $\mathrm{cm}^{-3}$, which is superior to the previously reported. ${ }^{32-36}$

Excellent mechanical performance of supercapacitor device is particularly important in portably flexible electronic products. Therefore, to further study the mechanical flexibility of the asfabricated $\mathrm{Co}_{3} \mathrm{O}_{4} @ \mathrm{Co}_{9} \mathrm{~S}_{8}$ nanowalls//AC ASCs device under real conditions, a device bended experiments at various angles and its CV measurements are carried out. Fig. 5a shows the pictures of the ASC device with a bending angle of $0^{\circ}, 45^{\circ}, 90^{\circ}$, and $180^{\circ}$, the corresponding CV curves at a scan rate of $100 \mathrm{mV} \mathrm{s}^{-1}$ is showed in Fig. 5b. The shape and the area of CV curves remain almost the same, revealing that the hybrid electrode has excellent mechanical properties. To further test the feasibility of practical application of $\mathrm{Co}_{3} \mathrm{O}_{4} @ \mathrm{Co}_{9} \mathrm{~S}_{8} / / \mathrm{AC}$ ASC, the devices are used to drive a $5 \mathrm{~mm}$ diameter LEDs, as shown in Fig. $5 \mathrm{c}$. The ASC can successfully power one LEDs (3.2 V) for $5 \mathrm{~min}$ after full charging. Furthermore, the cycling performance of $\mathrm{Co}_{3} \mathrm{O}_{4} @ \mathrm{Co}_{9} \mathrm{~S}_{8} / / \mathrm{AC}$ ASCs is also a key factor to evaluate the supercapacitor performance, and thus the ASC device is cycled for 10000 cycles between 0-
$1.5 \mathrm{~V}$ at a current density of $20 \mathrm{~mA} \mathrm{~cm}{ }^{-2}$, as seen in Fig. $5 \mathrm{~d}$. This asymmetric supercapacitor device shows excellent long-term cycle stability with the retention rate of $86.5 \%$ after 10000 cycles.

\section{Conclusions}

In summary, $\mathrm{Co}_{3} \mathrm{O}_{4} @ \mathrm{Co}_{9} \mathrm{~S}_{8}$ nanowalls as supercapacitor electrode materials are successfully synthesized on $\mathrm{Ni}$ foam by a hydrothermal method. $\mathrm{Co}_{3} \mathrm{O}_{4}$ nanosheets as the base substrate for $\mathrm{Co}_{9} \mathrm{~S}_{8}$ deposition can improve the cyclic stability of the electrode and the synergistic effect of these electrodes leads to an excellent electrochemical performance for the as-prepared $\mathrm{Co}_{3} \mathrm{O}_{4} @ \mathrm{Co}_{9} \mathrm{~S}_{8}$ nanowalls. Assembled asymmetrical supercapacitors exhibit high energy density and power density, which can to drive a blue LED lamp for $5 \mathrm{~min}$. In addition, the asymmetric supercapacitor has excellent mechanical properties and long cycle stability.

\section{Conflicts of interest}

There are no conflicts to declare.

\section{Acknowledgements}

This work was supported by Nature Science Fund of Liaoning Province (No. 20170540671). 


\section{References}

1 D. V. Pham, R. A. Patil, C. C. Yang, W. C. Yeh, Y. Liou and Y. R. Ma, Nano Energy, 2018, 47, 105-114.

2 W. Jiang, F. Hu, Q. Y. Yan and X. Wu, Inorg. Chem. Front., 2017, 4, 1642-1648.

3 N. P. Sari, D. Dutta, A. Jamaluddin, J. K. Chang and C. Y. Su, Phys. Chem. Chem. Phys., 2017, 19, 30381-30392.

4 D. P. Zhao, F. Hu, A. Umar and X. Wu, New J. Chem., 2018, 42, 7399-7406.

5 X. Hu, W. Zhang, X. Liu, Y. Mei, Y. Mei and Y. Huang, Chem. Soc. Rev., 2015, 44, 2376-2404.

6 C. Liu, W. Jiang, F. Hu, X. Wu and D. F. Xue, Inorg. Chem. Front., 2018, 5, 835-843.

7 L. L. Xing, K. J. Huang and L. X. Fang, Dalton Trans., 2016, 45, 17439-17446.

8 G. P. Xiong, P. G. He, D. N. Wang, Q. Q. Zhang, T. F. Chen and T. S. Fisher, Adv. Funct. Mater., 2016, 26, 5460-5470.

9 X. Wu and S. Y. Yao, Nano Energy, 2017, 42, 143-150.

10 T. Zhai, L. M. Wan, S. Sun, Q. Chen, J. Sun, Q. Y. Xia and H. Xia, Adv. Mater., 2017, 29, 1604167.

11 L. Xing, Y. D. Dong, F. Hu, X. Wu and A. Umar, Dalton Trans., 2018, 47, 5687-5694.

12 X. Wu, Z. C. Han, X. Zheng, S. Y. Yao, X. Yang and T. Y. Zhai, Nano Energy, 2016, 31, 410-417.

13 N. Jabeen, A. Hussain, Q. Y. Xia, S. Sun, J. W. Zhu and H. Xia, Adv. Mater., 2017, 29, 1700804.

14 Y. Liu, Y. Jiao, Z. L. Zhang, F. Y. Qu, A. Umar and X. Wu, ACS Appl. Mater. Interfaces, 2014, 6, 2174-2184.

15 H. Xia, C. Y. Hong, X. Q. Shi, B. Li, G. L. Yuan, Q. F. Yao and J. P. Xie, J. Mater. Chem. A, 2015, 3, 1216-1221.

16 Y. Jiao, Y. Liu, B. S. Yin, S. W. Zhang, F. Y. Qu and X. Wu, Nano Energy, 2014, 10, 90-98.

17 C. Liu and X. Wu, Mater. Res. Bull., 2018, 103, 55-62.

18 S. W. Zhang, B. S. Yin, H. Jiang, F. Y. Qu, A. Umar and X. Wu, Dalton Trans., 2015, 44, 2409-2415.

19 M. Zhu, Y. Huang, Y. Huang, H. Li, Z. Wang, Z. Pei, Q. Xue, H. Geng and C. Zhi, Adv. Mater., 2017, 29, 1605137.
20 F. Y. Liu, X. Chu, H. T. Zhang, B. B. Zhang, H. Su, L. Jin, Z. X. Wang, H. C. Huang and W. Q. Yang, Electrochim. Acta, 2018, 269, 102-110.

21 H. Y. Liang, J. H. Lin, H. N. Jia, S. L. Chen, J. L. Qi, J. Cao, T. S. Lin, W. D. Fei and J. C. Feng, J. Power Sources, 2018, 378, 248-254.

22 S. Kumar, G. Saeed, N. H. Kim and J. H. Lee, J. Mater. Chem. A, 2018, 6, 7182-7193.

23 Z. C. Han, X. Zheng, S. Y. Yao, H. H. Xiao, F. Y. Qu and X. Wu, Appl. Surf. Sci., 2016, 365, 240-244.

24 M. Kim, J. Choi, I. Oh and J. Kim, Phys. Chem. Chem. Phys., 2016, 18, 19696-19704.

25 F. Du, X. Q. Zuo, Q. Yang, G. Li, Z. L. Ding, M. Z. Wu, Y. Q. Ma, S. W. Jin and K. R. Zhu, Electrochim. Acta, 2016, 222, 976-982.

26 G. H. Cheng, T. Y. Kou, J. Zhang, C. H. Si, H. Gao and Z. H. Zhang, Nano Energy, 2017, 38, 155-166.

27 Q. Wang, L. Jiao, H. Du, Y. Si, Y. Wang and H. Yuan, J. Mater. Chem. A, 2012, 22, 21387-21391.

28 P. Sennu, V. Aravindan and Y. S. Lee, J. Power Sources, 2016, 306, 248-257.

29 Y. Zhao, L. F. Hu, S. Y. Zhao and L. M. Wu, Adv. Funct. Mater., 2016, 26, 4085-4093.

30 A. L. Dang, T. H. Li, C. Y. Xiong, T. K. Zhao, Y. D. Shang, H. G. Liu, X. D. Chen, H. Li, Q. Zhuang and S. Z. Zhang, Composites, Part B, 2018, 141, 250-257.

31 M. Suominen, P. Damlin, S. Granroth and C. Kvarnstrom, Carbon, 2018, 128, 205-214.

32 M. F. El-Kady, V. Strong, S. Dubin and R. B. Kaner, Science, 2012, 335, 1326-1330.

33 L. Yuan, B. Yao, B. Hu, K. Huo, W. Chen and J. Zhou, Energy Environ. Sci., 2013, 6, 470-476.

34 L. Yuan, X. H. Lu, X. Xiao, T. Zhai, J. Dai, F. Zhang, B. Hu, X. Wang, L. Gong, J. Chen, C. Hu, Y. Tong, J. Zhou and Z. L. Wang, ACS Nano, 2012, 6, 656-661.

35 Z. J. Fan, J. Yan, T. Wei, L. J. Zhi, G. Q. Ning, T. Y. Li and F. Wei, Adv. Funct. Mater., 2011, 21, 2366-2375.

36 D. Kong, C. Cheng, Y. Wang, J. I. Wong and Y. Yang, J. Mater. Chem. A, 2015, 3, 16150-16161. 